\title{
Capacity building: A missing piece in Nepal's plan for prevention and control of non-communicable diseases
}

\section{Vaidya A}

Abhinav Vaidya, Professor, Department of Community Medicine, Kathmandu Medical College, Kathmandu, Nepal.

DOI: https://doi.org/10.3126/jkmc.v7i4.23295

$\mathrm{N}$ on-communicable diseases (NCDs) kill every two out of every three people in the world'. Four out of five of these NCD-related deaths occur in the low and middle-income countries and it is expected that this proportion will rise in future ${ }^{2}$. In Nepal, 60 percent of disability-adjusted life-years is attributed to $\mathrm{NCDs}^{3}$. Risk factors such as tobacco and alcohol consumption, indoor air pollution, high blood pressure and high body mass index are high in Nepalese population ${ }^{4}$. While 18.5 percent of adults in Nepal smoke, 17.4 percent are current drinkers. Only one percent of the population eat adequate fruits and vegetables. More than a quarter have high body mass index (25.6 percent) or high blood pressure (25.7 percent) $)^{4}$. Indeed, concerted public health approaches are needed to combat NCDs ${ }^{5}$.

Focused almost entirely on infections, malnutrition and reproductive health for most of the Millennium Development Goals period, it is only recently that the global health leaders have woken up to the severity and impact of the NCDs ${ }^{6}$. Nevertheless, important headways have been made on a global scale to curb the $\mathrm{NCDs}^{7}$, with clear targets, such as a 25 percent reduction in premature mortality due to the major NCDs, set for $2025^{8}$. Nepal vouched to achieve these global NCD targets through its key document: Nepal's Multisectoral Action Plan for the Prevention and Control of NCDs (2014-2020) 9 .

NCDs are multi-factorial in origin, and their control should therefore also be multisectoral. For this, in accordance with the global consensus, four key strategic action areas have been identified in Nepal's Multisectoral Action Plan': Area 1 (Advocacy, partnership and leadership); Area 2 (Healthy lifestyle and reduction of major NCD risk factors); Area 3 (Health system strengthening for early detection and management of NCDs); and Area 4 (Surveillance, research, monitoring and evaluation). While the plan details out on who needs to do what and

Address for correspondence

Dr. Abhinav Vaidya

Professor, Department of Community Medicine,

Kathmandu Medical College,

Kathmandu, Nepal

E-mail:dr.abhinavaidya@gmail.com by when, it does not speak about whether the country has adequate capacity in terms of skills and human resources to carry these works, nor does it delineate the strategies to build the capacity.

Indeed, if we are to meet the NCDs targets, it is critical that we take heed of the available human resources for health $(\mathrm{HRH})$, and human resources beyond health. In this regard, Nepal's human resources working on NCDs can be segregated into three mutually un-overlapping categories: (1)Researchers and academicians, represented by a sizeable number of young graduates conducting observational and primary-preventive or health promotional interventional studies, mostly at community level ${ }^{10}$; (2) Clinicians and primary healthcare workers, which include a range of $\mathrm{HRH}$ with focus on curative medicine: from specialists and super-specialists practicing in urban tertiary centers to grass root level workers at the basic health facility level such as health posts; and, (3)Public health managers and policymakers, who are public health administrators and have experiences drawn mostly from prevention and control of infections, malnutrition, and maternal and child health problems. Besides the above mentioned HRH, combating NCDs require proactive involvement of wide range of other actors such as politicians, civil society, commerce, education and agriculture sectors. The local ('palika') level government, in particular, has become an indispensable stakeholder with the decentralization of health-related decision, implementation and outputs at the local level.

From the HRH management and point to prevent and control NCDs in Nepal, there are two major challenges. The first challenge is the intricacy to bring about synergistic collaboration among the various NCDs stakeholders for a cohesive endeavor targeted towards $\mathrm{NCDs}^{5}$. Currently, the NCD-targeted efforts are sporadic, infrequent, inadequate, and un-coordinated. The second challenge is insufficient capacity of the existing $\mathrm{HRH}$ to deal with NCDs. The fact that low-income countries (such as Nepal) have low capacity to combat the burgeoning epidemic of NCDs has been well realized in global forums, where the urgency, context, complexity, 
and resource constraints have been well articulated ${ }^{11}$. Various organizations have sporadically addressed this in the recent past, for example, enhancing global NCDs advocacy capacity ${ }^{12}$, and capacity building in research ${ }^{13}$. However, at the national level, it is evident that the Multisectoral Action Plan for NCDs has not adequately addressed the issue of capacity building. It is therefore worthwhile to discuss capacity building and its need in the four strategies areas as outlined in the Multisectoral Action Plan:

\section{Area 1 (Advocacy, partnership and leadership)}

Though many organizations are working on advocacy, there is no united voice for most of the NCD-related issues. There are disease-specific groups such as Nepal Diabetes Society, Nepal Hypertension Society, Nepal Heart Foundation, Nepal Cancer Relief Society, etc. but not all of these organizations are forceful advocates. There is Nepal NCD Alliance with members from some of the above-mentioned societies that need sharper claws to make some impact. On the other hand, civil society organizations such as the Resource Centre Primary Health Care (RECPHEC) have successfully championed the battle against tobacco in Nepal. Of late, The Nepal NCDI Poverty Commission has emerged as a strong force to catapult the advocacy effort for NCDs in Nepal, particularly for the 'poorest billion'14. Besides advocacy, partnership and leadership are also absolutely crucial considering the multisectoral facets of NCDs. These traits and skills may not be naturally present in an individual or an organization, and therefore, must be cultivated among the HRH and other stakeholders of NCDs.

\section{Area 2 (Healthy lifestyle and reduction of major NCD risk factors)}

There is a major crunch of $\mathrm{HRH}$ that is trained in promoting healthy lifestyle in a scientific and comprehensible way. Currently, emphasis is on health education rather than health promotion. Nepal Health Education, Information and Communication Centre (NHEICC), under the Department of Health Services, is the state-owned agency that produces NCDs-related health educational materials and distributes them through the governmental outlets. In addition, health counseling is an important component of the Package of Essential Non-Communicable Diseases (PEN) ${ }^{15}$. Capacity building to incorporate and enhance innovative and practical-oriented health promotional activities is needed to bring about actual behavioural changes. Further, successful initiatives for promoting healthy diet and improved physical activity such as the Heart-health Associated Research, Dissemination and Intervention in the Community (HARDIC) Trial needs to be scaled up ${ }^{16,17}$.

\section{Area 3 (Health system strengthening for early detection and management of NCDs)}

For health system strengthening, a breakthrough has recently taken place with the introduction and expansion of the Package of Essential Non-Communicable Diseases $(\mathrm{PEN})^{15}$. Begun as pilot projects in two districts in 2017, the government has expanded it further and intends to roll out the package to all the 77 districts soon. However, because of logistic and financial constraints, the PEN package does not train health workers at all levels in these districts ${ }^{18}$. Most of the time, it is only the health facility in-charge who gets the PEN training whereas NCD patients are attended by all the health workers. Another gap is the unrealistic expectation that the PEN package would spontaneously transfer from the health institutes to the community through health promotional activities and timely referral. But unless efforts are made to enhance the capacity of the community level workers and community members, it shall be unrealistic to expect this spillover.

\section{Area 4 (Surveillance, research, monitoring and evaluation)}

The last decade has witnessed a massive surge in NCD-related research in Nepal. Almost all of them are academically backed up and funded by universities or agencies outside of Nepal. Besides, the state-run Nepal Health Research Council (NHRC) has been the frontrunner in NCD risk factors surveillance via the WHO NCDs STEPs survey $4^{4}$. The Multisectoral Action Plan assigns NHRC as the locus point for NCD related research and surveillance, but the road is uphill for the NHRC until its capacity is quantitatively and qualitatively upgraded to deliver what is expected out of it. NHRC should also bring the NCD-research scholars under its umbrella to synthesize NCD-related evidence. In addition, there is a need to retune the government agencies and other stakeholders to monitor and evaluate health programs from NCDs perspective. In fact, a positive move is already happening in this direction with Kathmandu University and NHRC already joining hands to train Nepalese scholars to enhance their capacity in translational research to address cardiovascular diseases in Nepa ${ }^{19}$. In addition, contributions are being made by institutes such as Kathmandu Medical College by organizing training workshops in specific NCD areas such as granting writing and digitization in cardiovascular health ${ }^{20}$.

\section{CONCLUSION}

To conclude, there is an urgent need to building capacity in Nepal so that the nation is well-equipped to combat the battle against NCDs. Efforts should be made to garner resources to ensure that capacity building is well addressed and applied in all the strategic areas 
of the Multisectoral Action Plan of Nepal. Clear visions are needed to address the current gaps in NCD-related services at various levels. Researchers and academicians

\section{REFERENCES}

1. Lozano R, Naghavi M, Foreman K, Stephen L, Shibuya K, Aboyans V, et al. Global and regional mortality from 235 causes of death for 20 age groups in 1990 and 2010: a systematic analysis for the Global Burden of Disease Study 2010. Lancet. 2012;380:2095-128. [DOI]

2. Alwan A. Global status report on non-communicable diseases 2010. Geneva: World Health Organization; 2011. [Full text]

3. World Health Organization. Disease and country estimates. Geneva: World Health Organization; 2013. [Cited 2018 Nov 5]. Available from: https:// www.who.int/healthinfo/global_burden_disease/ estimates/en/index $1 . h t m l$

4. Aryal KK, Neupane S, Mehata S, Vaidya A, Singh S, Paulin F, et al. Nepal non-communicable diseases risk factors: STEPS survey Nepal 2013. Kathmandu: Nepal Health Research Council.[Full text]

5. Diem G, Brownson RC, Grabauskas V, Shatchkute A, Stachenko S. Prevention and control of noncommunicable diseases through evidencebased public health: implementing the NCD 2020 action plan. Glob Health Promot. 2016 Sep;23(3):513.[DOI]

6. Beaglehole R, Bonita R, Alleyne G, Horton R, Li L, Lincoln $P$, et al. for The Lancet NCD Action Group. UN high-level meeting on non-communicable diseases: addressing four questions. Lancet. 2011;378:449-55.[DOI]

7. World Health Organization. 2008-2013 action plan for the global strategy for the prevention and control of noncommunicable diseases. Geneva: World Health Organization; 2008. [Full text]

8. World Health Organization. Global action plan for the prevention and control of non-communicable diseases 2013-2020. Geneva: World Health Organiation; 2013.[DOI]

9. Ministry of Health and Population, Nepal. Multisectoral Action Plan for the Prevention and Control of Non Communicable Diseases (20142020). [Cited 2018 Oct 7]. Available from: http:// www.searo.who.int/nepal/mediacentre/ncd multisectoral_action_plan.pdf.[Full Text]

10. Vaidya A. Communicating the role of academia in the control of non-communicable diseases: identification, involvement and institutionalization. Health Prospect: Journal of Public Health.Jan 2015; 13: 28-29.[DOI]

11. International Union for Health Promotion and must also be taken as a co-workforce by the government, especially in order to narrow the academia-policy gaps in the area of NCDs.

Education (IUHPE), US Centers for Disease Control and Prevention (CDC). Policy Brief: Building global capacity for non-communicable diseases (NCD) prevention. [Cited 2018 Nov 12]. Available from: http://www.iuhpe.org/index.php/en/iuhpethematic-resources/295-on-non-communicablediseases.

12. Shilton $T$, Champagne B, Blanchard C, Ibarra L, Kasesmup V. Towards a global framework for capacity building for non-communicable disease advocacy in low- and middle-income countries. Glob Health Promot. 2013 Dec;20(4 Suppl):6-19.1 [PubMed]

13. Sturke R, Vorkoper S, Duncan K, Levintova $M$, Parascondola M. Addressing NCDs through research and capacity building in LMICs: lessons learned from tobacco control. Glob Health Action. 2016 Aug 19;9:32407.[PubMed]

14. The Lancet NCDI Poverty Commission. The Nepal NCDI Commision. Available from: http://www. ncdipoverty.org/nepal-report.

15. Ministry of Health and Population, Government of Nepal. Non-communicable diseases. [Cited 20180ct 20]. Available from: http://mohp.gov.np/ eng/program/free-health-programme/pen.

16. Vaidya A, Oli N, Eiben G, Krettek A. The Hearthealth Associated Research, Dissemination and Intervention in the Community (HARDIC) Trial for Nepalese Mothers regarding Diet and Physical Activity: A Process Evaluation. Kathmandu Univ Med J 2017 Apr-Jun;58(2):107-16.[Full text]

17. Vaidya A. Heart health promotion: From community level. In: The Himalayan Times. [Cited 20180ct 20]. Available from: https://thehimalayantimes.com/ opinion/heart-health-promotion-community-level/

18. Aryal BK, Daud M, Thapa A, Mahotra A, Magar SA, Malla CK. Assessment of Health Facilities for Implementation of Non-communicable Disease Package. J Nepal Health Res Counc 2018 AprJun;16(39): 149-55.[Full text]

19. Koju R. Translational Research Capacity Building Initiative to Address Cardiovascular Diseases in Nepal. [Cited 20180ct 5]. Available from: http:// grantome.com/grant/NIH/U24-HL136789-01. [DOI]

20. Kathmandu Medical College Public Limited. Workshop on Grant Writing and Digitalization for Cardiovascular Health Research. Kathmandu Medical College Times. Issue 17; 2018 Dec. [Cited 2018 Dec 20]. Available from: https://www.kmc. edu.np/kmctimes/kmc_times_issuse16.pdf [DOI] 